\title{
Colloidal properties and stability of olive oil-in water emulsions stabilized by starch particles
}

\author{
Umer Farooq, Carla Di Mattia*, Marco Faieta, Federica Flamminii, Paola Pittia \\ Faculty of Bioscience and Technology for Agriculture, Food and Environment, University of Teramo, Teramo, Italy
}

*Corresponding Author: Carla Daniela Di Mattia, Faculty of Bioscience and Technology for Agriculture, Food and Environment, University of Teramo, Via Renato Balzarini 1, 64100 Teramo, Italy. Email: cdimattia@unite.it

Received: 17 June 2021; Accepted: 21 August 2021; Published: 8 October 2021

(c) 2021 Codon Publications

OPEN ACCESS (C) (1)(2)(2)

PAPER

\begin{abstract}
In this study, olive oil-in-water emulsions ( $30 \%$ oil, v/v) were prepared by using high-pressure homogenization and different concentrations of modified corn starch particles $(6-10 \% \mathrm{w} / \mathrm{v})$. After a preliminary physical characterization, the modified starch particles were used to produce olive oil-in water $(\mathrm{o} / \mathrm{w})$ emulsions whose droplet size and distribution, flow behavior, microstructure, and physical stability were evaluated. The stabilization by Pickering phenomena was observed, as well as the formation of a starch network able to entrap oil particles. Increasing the starch concentration enhanced the emulsion physical stability by improving the oil particles' stabilization within the starch network.
\end{abstract}

Keywords: corn starch; high pressure homogenization; olive oil; o/w emulsions; Pickering emulsions

\section{Introduction}

Oil-in-water (o/w) emulsions are amongst the most widespread multiphasic systems and, because of their role in providing a proper structure, desirable appearance, and mouthfeel properties to lipid-containing matrices, they are of crucial importance in a wide range of emulsified products from the food, pharmaceutical, and cosmetic industry (Yang et al., 2017).

In recent years, studies on Pickering stabilization of the oil/water interface by solid particles which get absorbed on the interfacial layer and act as a physical barrier have been progressively increasing (Tavernier et al., 2016; Xiao et al., 2016). Indeed, due to the high adhesion energy at the liquid-liquid interface, particle adsorption is considered to be much stronger in comparison to low molecular weight surfactants (McClements and Gumus, 2016; Ravera et al., 2020; Wu and Ma, 2016). Solid particles can thus reside at the interface of droplets, thereby providing Pickering emulsions with high resistance against coalescence and instability phenomena like Ostwald ripening.

In preliminary works, inorganic particles such as clay, silica, and latex were used as stabilizers in Pickering emulsions (Abend et al., 1998; Aveyard et al., 2003; Binks and Lumsdon, 2000); however, due to rapid biodegradability, poor bioavailability, and above all, the increasing attention of consumers toward more natural ingredients, their use in the food industry was largely limited, highlighting the need of using natural biopolymer particles as stabilizers in Pickering emulsions (Berton-Carabin and Schroën, 2015; Dickinson, 2012).

Recently, starch has obtained an increased interest as a potential stabilizer biopolymer in Pickering emulsions for both food and pharmaceutical applications thanks to its low cost, high natural availability, nontoxicity, ease in production, and high bioavailability (Ge et al., 2017; Lee and Chang, 2019; McClements and Gumus, 2016; Tavernier et al., 2016). However, native starch particles are generally 
not hydrophobic and present a low capacity to absorb at oil/water interfaces. Among the methods available to increase starch hydrophobicity, esterification is one of the most commonly used (Khan and Ahmad, 2013). Indeed, esterification improves the performance of starches by making them more amphiphilic and hence more suitable for the stabilization of emulsions. Esterification is a commonly used process in which an acid or its derivative is used to react with the hydroxyl groups of starch, replacing them with ester groups which are more hydrophobic (Fang et al., 2002). As a result, a more hydrophobic starch with reduced retrogradation and improved emulsifying properties is produced (Ghanbarzadeh et al., 2011; Xie and Liu, 2004; Zhou et al., 2016). For esterification purposes, among the various organic acids used, citric acid, a trifunctional carboxylic acid, is most widely used due to its low cost, high effectiveness, and environmental sustainability (Jiangping et al., 2019).

High pressure homogenization (HPH) is a technology applied for obtaining finely dispersed $\mathrm{o} / \mathrm{w}$ emulsions characterized by higher physical stability and resistance. In general, a pre-homogenized, coarse, pre-emulsified mix of the oil and water phases is passed through a small valve under dynamic pressure to produce the final fine dispersion (Friberg et al., 2003). It is well known that HPH induces starch gelatinization; however, this highpressure-induced gelatinization is significantly different form the heat-induced gelatinization as starch granules retain their structure and only little amount of amylose oozes out (Rubens and Heremans, 2000; Stute et al., 1996). Moreover, high-pressure-treated starch granules comprise two different zones: the inner zone, which is completely destroyed due to high pressure and forms a gel-like network, and an outer zone, which largely remains undisturbed (Błaszczak et al., 2005). So far the use of $\mathrm{HPH}$ is largely focused on stabilizing the traditional emulsions using the chemical surfactants and biomolecules while the use of HPH in stabilizing the Pickering emulsions is rarely investigated. To the best of authors knowledge so far no study is published which investigate the use of HPH in stabilizing the Pickering emulsions with starch particles, using olive oil as dispersed phase. While $\mathrm{HPH}$ is largely used to produce emulsions with conventional emulsifiers, its use in the formation of Pickering emulsions has been scarcely investigated and, to the best of authors' knowledge, no studies are available in the literature on its application to olive oil o/w emulsions stabilized with starch particles. Currently, very few works are available on starch-stabilized olive oil emulsions as well (Farajpour et al., 2020; Qian et al., 2020); in the work by Quian and coworkers, the use of corn starch nanocrystals with increasing levels of acetylation was explored to produce, by means of a rotor-stator device, Pickering olive oil emulsions characterized by different levels of viscoelasticity. In another work, Pickering olive oil emulsions stabilized by starch-zein nanoparticle complexes were studied as starting material to produce biocomposite edible films (Farajpour et al., 2020; Qian et al., 2020).

The aim of this work was, thus, to study the colloidal properties, flow behavior, and physical stability of olive oil-in-water emulsions obtained by means of HPH and stabilized with corn starch granules modified by esterification with citric acid. In a preliminary step, the physical properties, microstructure, and size of corn starch granules after esterification were initially evaluated. Moreover, to evaluate any likely effect induced by high dynamic pressure, the properties of the modified starch subjected to HPH at conditions similar to those applied during the emulsion preparation were also studied. Finally, the $\mathrm{o} / \mathrm{w}$ emulsions were characterized for droplet size and distribution, flow properties, and physical stability over a storage time of 30 days.

\section{Material and Methods}

\section{Experimental plan}

The investigation was carried out according to the following steps:

Step I: Starch particles' modification by esterification with citric acid.

Step II: Emulsifying activity of modified starch toward olive oil.

Step III: Characterization of emulsions' colloidal properties and physical stability.

\section{Materials}

Native corn starch was provided by Roquette Italia S.P.A. (Cassano Spinola, Italy). Commercial extra virgin olive oil was purchased from a local market. Anhydrous citric acid (99.5\% purity) was purchased from Sigma-Aldrich (Steinheim, Germany). All other chemicals were of analytical grade.

\section{Methods}

\section{Starch particles' modification by esterification}

Native corn starch (NS) was esterified with citric acid according to the method of Kim et al. (2017) with some modifications. Briefly, citric acid (30\% on starch dry basis) was dissolved in $50 \mathrm{~mL}$ distilled water and subsequently the $\mathrm{pH}$ of the solution was adjusted to 3.5 using $10 \mathrm{M}$ $\mathrm{NaOH}$. An aliquot of $50 \mathrm{~g}$ of NS was added in the citric acid solution with continuous mixing and the mixture was then left at room temperature for $16 \mathrm{~h}$. The mixture 
was than dried in a hot air oven at $60^{\circ} \mathrm{C}$ for $3-4 \mathrm{~h}$ till the 5-10\% (w/w) moisture content was achieved followed by grinding and drying at $140^{\circ} \mathrm{C}$ for $4 \mathrm{~h}$. The dried starch was then ground using a pestle and mortar and washed with distilled water thrice to remove the leftover citric acid. Finally, the starch was dried at $45^{\circ} \mathrm{C}$ for $24 \mathrm{~h}$ and finely powdered by a ball-miller (Fritsch, Idar-Oberstein, Germany) and passed through a 90-micron sieve.

\section{Preparation of o/w Pickering emulsions}

The $30 \%(\mathrm{v} / \mathrm{v})$ o/w emulsions were prepared by mixing the modified starch (MS) suspension at different concentrations $(6.0,8.0,8.5,9.0,9.5$, and $10.0 \%)(\mathrm{w} / \mathrm{v})$ and olive oil with a rotor-stator device (DI 25 basic, IKA, Stufen, Germany) at 20,000 rpm for $2 \mathrm{~min}$; the pre-emulsions were then submitted to HPH using a Panda Plus 2000 homogenizer (GEA, Parma, Italy) at 55 bar with a circulation time of $5 \mathrm{~min}$.

\section{Degree of substitution of esterified starch}

The method of Jeon et al. (1999) with some modifications was used to determine the degree of substitution (DS) of the modified starch. Both the native and modified starches $(1 \mathrm{~g})$ were slowly dissolved in the $10 \mathrm{~mL}$ solution of DMSO at $70^{\circ} \mathrm{C}$ for 10 min and left to cool down at ambient temperature. Then, after the addition of a few drops of phenolphthalein indicator, the solution was titrated against a standardized $0.05 \mathrm{M} \mathrm{NaOH}$ solution till a light pink color was attained as the end point. The DS values were calculated using the following equation (Zhang et al., 2017):

$$
\mathrm{DS}=\frac{0.162(\mathrm{~A} \times \mathrm{M} / \mathrm{W})}{1-[0.210(\mathrm{~A} \times \mathrm{M} / \mathrm{W})]}
$$

where, $\mathrm{A}=$ volume of $\mathrm{NaOH}$ used, $\mathrm{M}=$ molarity of $\mathrm{NaOH}$, and $\mathrm{W}=$ weight of the starch sample used.

\section{Particle size measurement of starch granules and $\mathrm{o} / \mathrm{w}$ emulsions}

The particle size distribution of starch granules and oil droplets in the emulsions was measured by laser diffraction (Mastersizer 3000, Malvern Instruments Ltd. Malvern, UK). For starch, a refractive index of 1.52 was used (Loisel et al., 1998). For emulsions, refractive indices of 1.33 and 1.59 were used for water and olive oil, respectively. Droplet size measurements are reported as particle size distribution curves and surface mean diameter $\left(D_{3,2}\right)$.

\section{Flow behavior of o/w emulsions}

The flow curves of Pickering emulsions were determined by using a controlled stress-strain rheometer (MCR 302, Anton Paar, Graz Austria) equipped with a concentric cylinder configuration. Flow curves were measured at $20^{\circ} \mathrm{C}$ at increasing shear rates from 3 to $300 \mathrm{~s}^{-1}$. The experimental data were modeled using the Power Law equation (Eq. 2)

$$
\sigma=\mathrm{K} \gamma^{\mathrm{n}}
$$

where $\sigma=$ shear stress $(\mathrm{Pa}), \mathrm{K}=$ consistency index, $\gamma=$ shear rate $(1 / \mathrm{s})$, and $\mathrm{n}=$ flow behavior (dimensionless).

\section{Physical stability of o/w emulsions}

The physical stability of emulsions was measured using the creaming index $(\mathrm{CI})$ during a storage period of 30 days at room temperature. Emulsions were photographed at 1-week intervals and the images were processed using Image J software. The cream volume was measured and the creaming index was obtained as a ratio between the total volume $\left(\mathrm{V}_{\mathrm{t}}\right)$ and cream volume $\left(\mathrm{V}_{\mathrm{c}}\right)$ using the following equation

$$
\text { Creaming Index }=\frac{\mathrm{V}_{\mathrm{c}}}{\mathrm{V}_{\mathrm{t}}} \times 100
$$

\section{Optical microscopy}

The microscopic observation of the Pickering emulsions was carried out using an Olympus-BX53 light microscope at $10 \times$ and $40 \times$ magnification. The photographs were taken with a 12-bit digital camera (QIQAM Fast 1394, Surrey, Canada) connected with the microscope. The starch was stained with Lugol's solution; samples were placed on the microscope slide and covered with a glass cover before observation.

\section{Scanning Electron Microscopy (SEM)}

A Scanning Electron Microscope (model Leica Cambridge, UK) at $5 \mathrm{kV}$ was used to evaluate the microstructural properties of esterified starch. About $100 \mathrm{mg}$ of sample with double-sided adhesive tape was mounted on the SEM stub, and to avoid the charging effect due to electron beam it was sputter coated with gold.

\section{Statistical analysis}

All experiments were performed at least in triplicates. The analysis of variance (ANOVA) was performed using SPSS version 24 (SPSS, Chicago, USA). Ducan's test was used for reporting the significance difference results at 95\% confidence level $(\mathrm{P}<0.05)$.

\section{Results and Discussion}

\section{Effect of citric acid treatment and HPH on corn starch particles}

The emulsifying ability of starch granules as Pickering particles toward o/w emulsions is highly dependent on 
their composition, structure, and granule size (Timgren et al., 2013). In order to evaluate any likely effect of $\mathrm{HPH}$ on starch particles' morphology and functionality, corn starch was preliminarily modified by using citric acid and then subjected to the homogenization process conditions used for emulsion preparation. It is known that HPH can significantly affect starch properties and induce gelatinization (Wang et al., 2008) ; however, in this work, pressure of homogenization was kept low (55 bar) to limit state transition of the starch particles dispersed in the aqueous phase.

In Figure 1, the microstructural properties of native (NS) and citric-acid-modified corn starch (MS) subjected to $\mathrm{HPH}$ (HPH-NS and HPH-MS) are shown, while in Figure 2 their particle size is reported as $\mathrm{D}_{3,2}$. Regardless of the treatments applied, all the starch samples were characterized by a poly-dispersed population. However, $\mathrm{HPH}$ significantly $(\mathrm{P}<0.05)$ reduced the particle size of both the native starch (Figure 1B) and modified corn starch (Figure 1D), as also confirmed by the results of the volume/surface $\left(D_{3,2}\right)$ and particle size of the samples (Figure 2). The size reduction was more evident on the citric-acid-modified corn starch whose median value was significantly lower $(\mathrm{P}<0.05)$ compared to native corn starch $(12.54 \pm 0.04 \mu \mathrm{m}$ and $20.84 \pm 0.12 \mu \mathrm{m}$, respectively), likely due to the structural modification of corn starch induced by the citric acid pretreatment.

The hydrophobic properties of starch particles as a consequence of both esterification and esterification in combination with the $\mathrm{HPH}$ process were evaluated by measuring the degree of substitution (DS). During the esterification process, hydrophobic groups are introduced to the amylose residues, causing an increase of the DS, resulting in enhanced surface active properties (Zhou et al., 2016). The DS of MS was $0.22 \pm 0.01$, significantly higher than that of NS whose DS value was equal to $0.01 \pm 0.00$, confirming the efficacy of the esterification process applied. This result is in agreement with literature data where significantly higher DS values were reported after esterification of maca starch with citric acid (Lee and Chang, 2019). HPH did not affect the hydrophobic properties of the starch particles of both native and modified starches as the DS of both HPH-NS and HPH-MS was not significantly different than the not homogenized sample (data not shown).

The changes induced in the morphology and microstructure of the NS and MS are highlighted in the SEM images
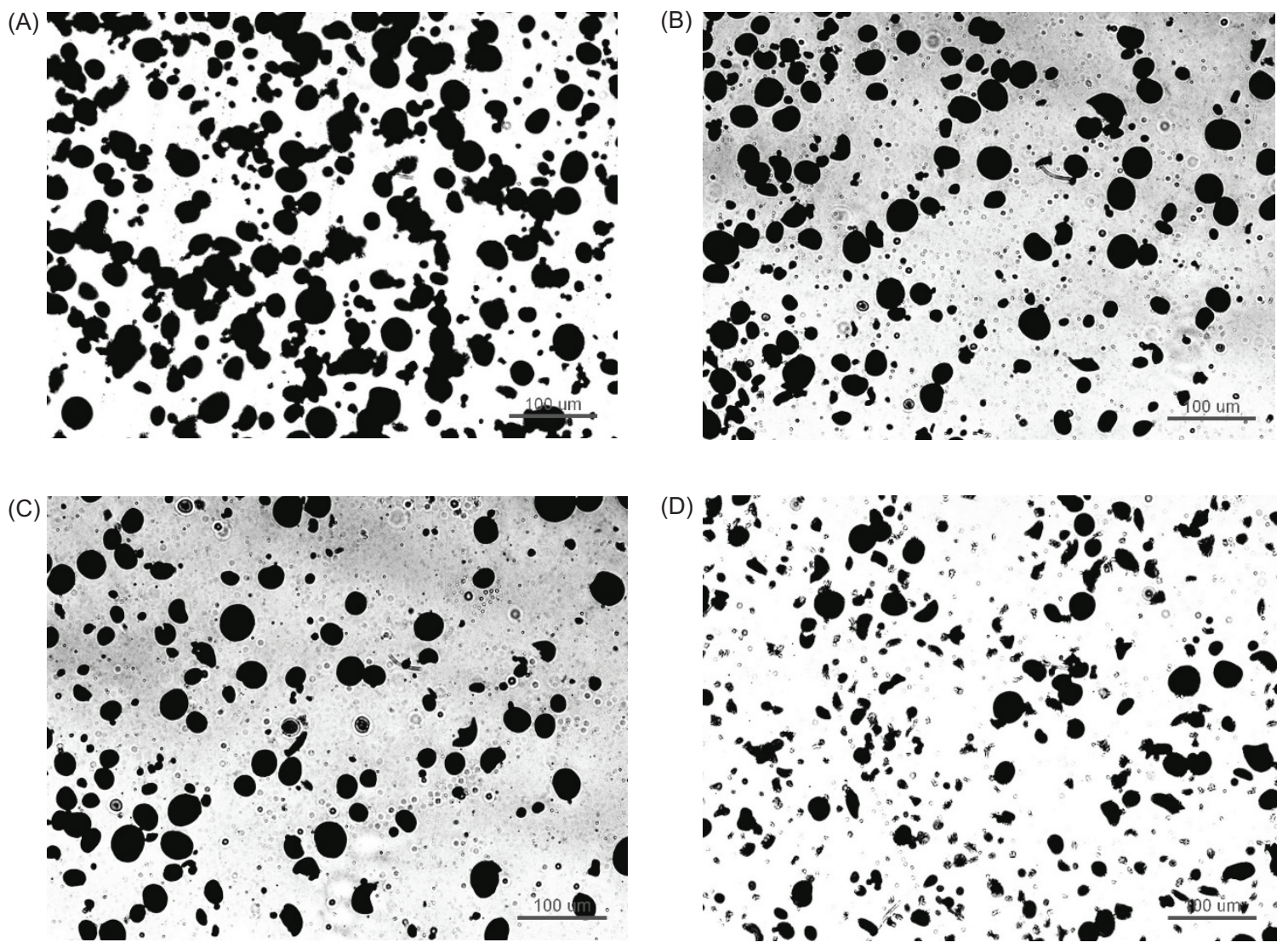

Figure 1. Micrographs of starch particles taken by light microscope: NS (A), HPH-NS (B), MS (C), HPH-MS (D). HPH: high pressure homogenization; NS: native starch; MS: modified starch. 
reported in Figure 3. NS granules (Figure 3A) present a smooth outer surface while after the citric-acid-modification slight groves and corrosion appeared on the surface of the MS granules (Figure 3B). However, overall, the esterification did not significantly alter the main structure of the starch granules or their size. These results are similar to those reported by other authors reporting that chemical modification of native starch only affects the outer surface of the granules while no changes in the morphology and structure of the starch granules occur (Mbougueng et al., 2012; Zhang et al., 2017). The surface modification of the starch granules induced by the esterification has been related to the weathering effect of acid hydrolysis (Alimi and Workneh, 2018).

\section{Emulsifying capacity of modified starch toward olive oil}

In order to study the emulsifying capacity of starch particles toward olive oil, suspensions of both native and

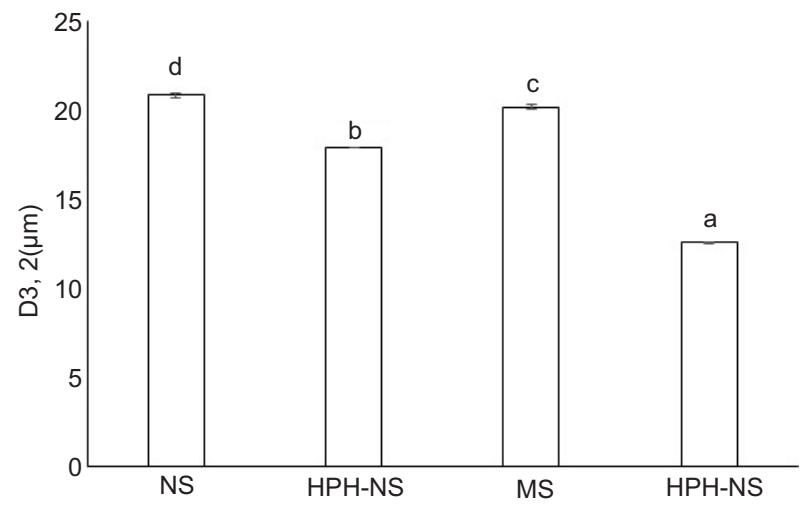

Figure 2. Particle size $\left(D_{3,2}\right)$ of the differently treated corn starch particles. Different letters on each bar indicate significant differences among the mean values $(P<0.05)$. NS: native starch; MS: modified starch; HPH: high pressure homogenization.

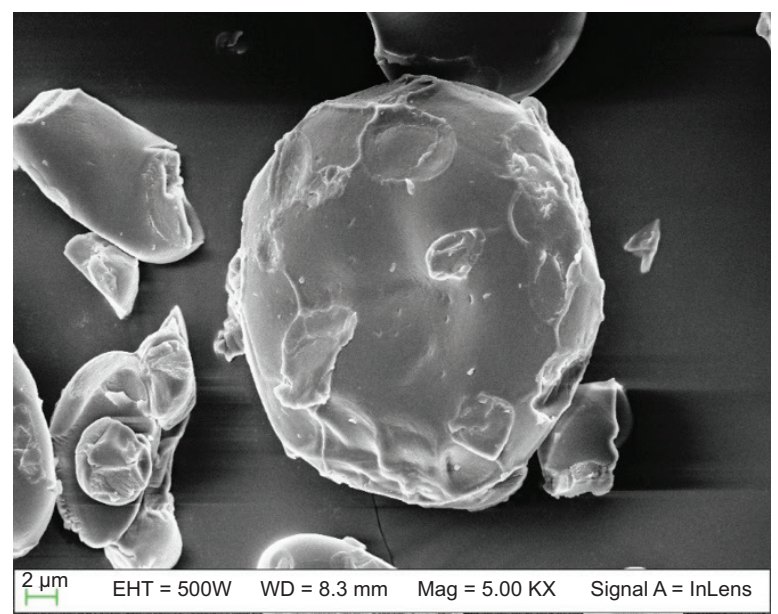

modified starches at increasing concentrations were used to prepare $\mathrm{o} / \mathrm{w}$ emulsions made of olive oil as dispersed phase (fixed concentration 30\%, v/v), homogenized by means of HPH. Regardless of the concentration tested, no emulsifying capacity was observed when NS was used as the emulsions readily destabilized; hence, NS was not further taken into consideration. On the contrary, fine olive oil o/w emulsions were obtained when MS was used as emulsifier: Figure 4 thus shows the size class and particle size distribution of the olive oil o/w emulsions prepared with MS in the concentration range of 6.0-10.0\% $(\mathrm{w} / \mathrm{v})$. Such a result can be related to the improvement of the emulsifying capacity due to the introduction of ester groups during modification (Lee and Chang, 2019). Indeed, some authors evidenced that esterification increases the amphiphilic properties of starch granules and this leads to a decrease of the surface tension between the oil-water interface with respect to that observed in the corresponding native, unmodified ones (Królikowska et al., 2017), favoring the formation and stabilization of the fine oil droplets formed during the homogenization process.

With regard to the dispersion degree, of all the MS concentrations tested, the particle size distribution was characterized by a high degree of polidispersity (Figure 4A) with at least three oil droplet populations with a relative maximum average at particle sizes of around 2, 5, and $50 \mathrm{~mm}$, respectively. At increasing starch concentrations, a progressive higher particle size was observed along with a relative higher amount of larger particles, with no variation in the size range distribution. This behavior was also reflected in the results of the surface mean droplet size $\mathrm{D}_{3,2}$ of the emulsified samples (Figure $4 \mathrm{~B}$ ) with the smaller droplet diameter observed in the emulsions made with lower starch concentration $(5.94 \pm 0.73 \mu \mathrm{m})$. Then, by increasing the starch concentration, the droplet particle size increased up to a plateau value of about

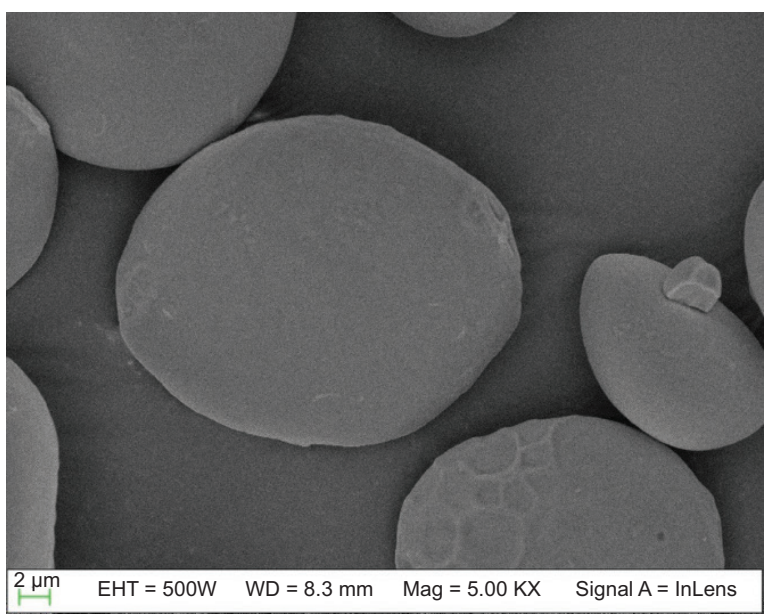

Figure 3. SEM micrographs of NS (A) and MS (B) particles (NS: native starch; MS: modified starch). 


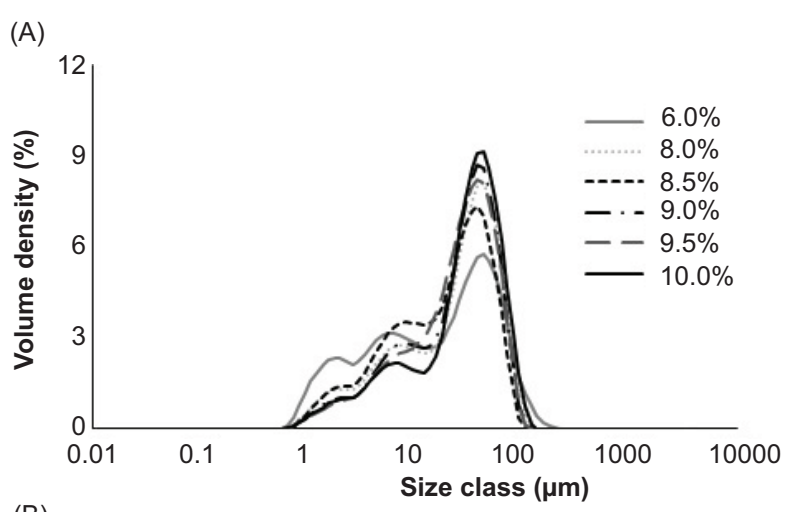

(B)

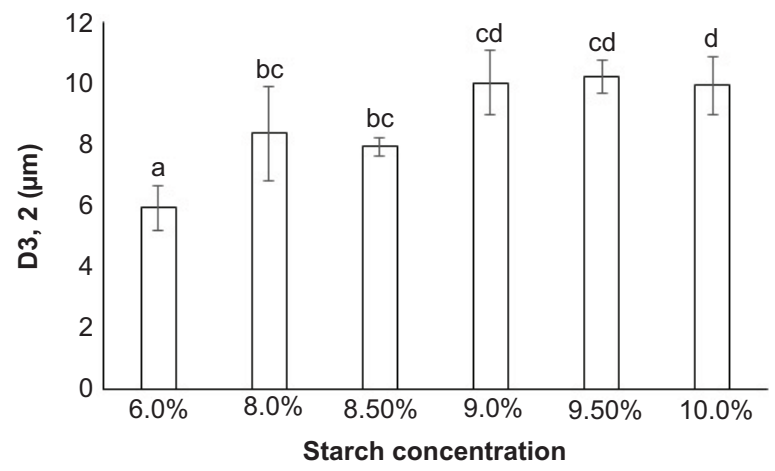

Figure 4. Droplet size distribution (A), and surface mean droplet size (B) of o/w Pickering emulsions prepared with different concentrations of modified corn starch. Different letters in the same columns indicate significant differences $(P<0.05)(n=3)$.

$10 \mu \mathrm{m}$. This result is in disagreement with data reported in the literature, as higher starch concentration allows more particles to be able to absorb at the oil/water interface and stabilize the interfacial layer and thus decrease the particle size (Li et al., 2013; Marefati et al., 2017). This disagreement could be due to several causes, such as a difference in the starch particles' properties and size; the emulsified systems, like the oil to water volume ratio; and the homogenization conditions used with respect to the current study.

However, it is worth observing that emulsions presented a surface mean droplet size lower or equal to $10 \mu \mathrm{m}$, which, according to some authors, indicates good emulsification capacity and emulsion stability toward physical destabilization phenomena such as creaming and flocculation, when compared to emulsion with larger droplets (Saari et al., 2016). So, it can be generally affirmed that in the range of concentrations tested and under the process conditions applied, the modified starch particles exerted good emulsifying properties, determining the formation of fine o/w olive oil dispersed systems.

Images of emulsions made with $9.5 \% \mathrm{MS}(\mathrm{w} / \mathrm{v})$ evaluated by light microscopy captured at two different magnifications are reported in Figure 5, as an example of systems' microstructure. The micrographs highlight that the emulsions present a complex structure where small oil droplets are dispersed in an aqueous phase that contains a large amount of starch (black spots in the images) that are in some cases interacting (Figure 5A), likely due to the effect of the high dynamic pressure during emulsification. Moreover, it could be clearly evidenced that oil droplets are stabilized by adsorbed starch particles (Figure 5B). As previously observed in the literature, the overall emulsified dispersed state of the emulsions can be due to both the Pickering mechanism by starch particles adsorbed on the o/w interface as well as the stabilization and immobilization of oil droplets within the starch, gel-like granules network formed during the $\mathrm{HPH}$ process (Dickinson, 2020). Indeed, it could be affirmed that during the high-pressure homogenization, the Pickering emulsions were stabilized by several mechanisms occurring simultaneously, which are the adsorption of starch particles on the oil/water interface, the release of amylose from the starch granules which formed complexes with the oil droplets, and the formation of the gel-like network of starch granules which immobilized the oil droplets. Indeed, these stabilization phenomena have been previously reported in Pickering emulsions prepared with corn starch under HPH (Meng et al., 2014; Villamonte et al., 2016).

\section{Flow behavior of Pickering olive oil emulsions}

Flow behavior of Pickering emulsions at different MS concentrations is reported in Figure 6. All dispersed systems presented a non-Newtonian shear-thinning behavior as, at increasing MS concentration, the shear stress increased. The shear-thinning behavior can be explained by a weak droplet association where the network underwent breakage as the shear force was increased, the rate of starch network deformation was higher than the reformation rate, resulting in lower viscosity because of reduced intermolecular resistance, behavior which has been previously observed for starch-stabilized o/w emulsions (Ye et al., 2017).

The experimental data were fitted by using a power law model $\left(\sigma=K \gamma^{\mathrm{n}}\right)$ where $\sigma$ is the shear stress $(\mathrm{Pa}), \mathrm{K}$ the consistency index, $\gamma$ the shear rate $(1 / \mathrm{s})$, and $n=$ flow behavior (dimensionless). The extent of shear-thinning behavior in a non-Newtonian fluid is calculated using the flow behavior ( $n)$. If the value of $n$ is $<1$, it is shear-thinning fluid and $>1$ indicates a shear-thickening fluid (Rezaei et al., 2017). In Table 1, the flow behavior (n) and consistency index (k) values of the differently made emulsions are summarized. All samples presented an $\mathrm{n}$ value $<1$ confirming the shear-thinning behavior; it significantly $(P>0.05)$ increased from 6.0 to $8.0 \%$ starch 
(A)

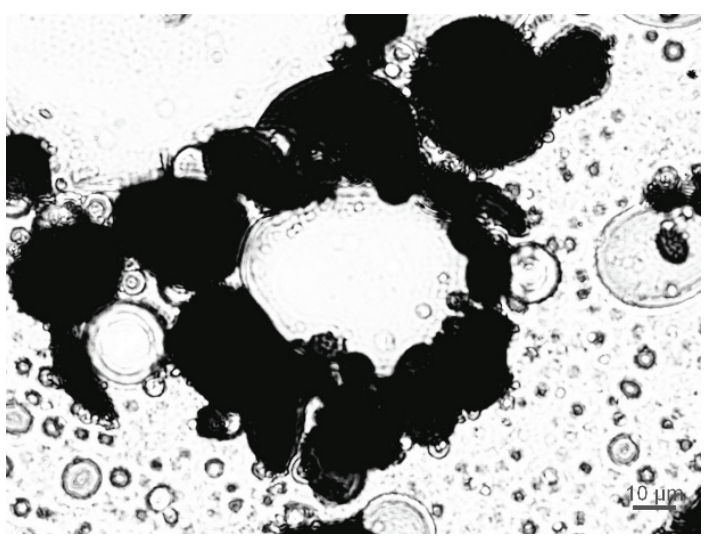

(B)

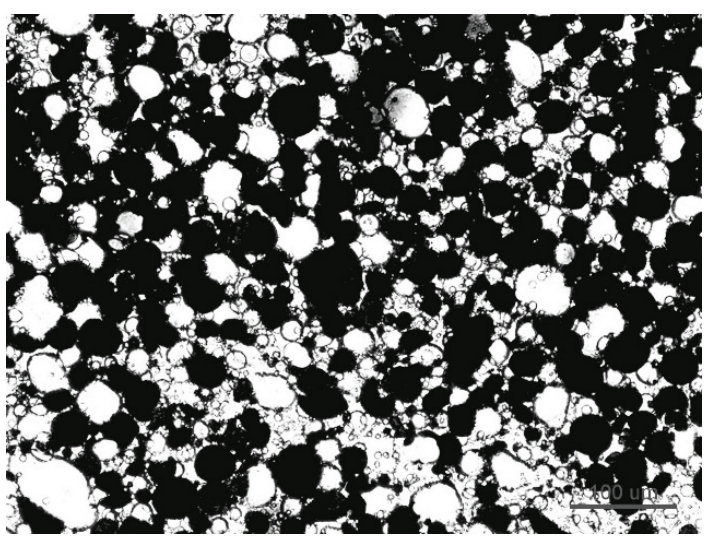

Figure 5. Optical microscope images of Pickering emulsions prepared with $9.5 \% \mathrm{MS}$ at different magnifications (10x in A, 40x in B). MS granules appear to be black in color (MS: modified starch).

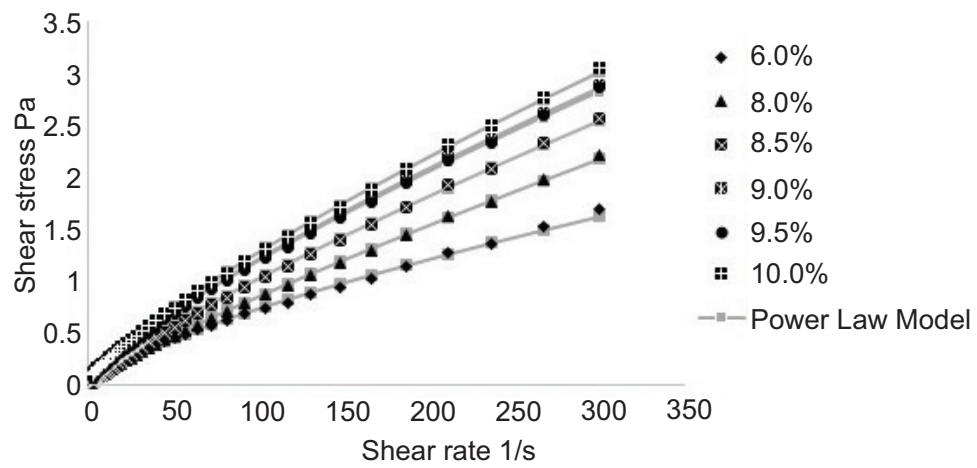

Figure 6. Flow behavior of the o/w Pickering emulsions prepared with different concentrations of modified corn starch (6.0$10.0 \% \mathrm{w} / \mathrm{w})$.

Table 1. Consistency index and flow behavior of the $30 \%$ o/w Pickering emulsions stabilized by high pressure homogenization and MS particles.

\begin{tabular}{|c|c|c|c|c|c|c|}
\hline & $\begin{array}{l}\text { MS } \\
6.0 \%\end{array}$ & $\begin{array}{l}\text { MS } \\
8.0 \%\end{array}$ & $\begin{array}{l}\text { MS } \\
8.5 \%\end{array}$ & $\begin{array}{c}\text { MS } \\
9.0 \%\end{array}$ & $\begin{array}{c}\text { MS } \\
9.5 \% \\
\end{array}$ & $\begin{array}{c}\text { MS } \\
10.0 \% \\
\end{array}$ \\
\hline K & $0.027^{a} \pm 0.01$ & $0.017^{a} \pm 0.01$ & $0.022^{a} \pm 0.00$ & $0.034^{a} \pm 0.01$ & $0.033^{a} \pm 0.01$ & $0.036^{a} \pm 0.01$ \\
\hline$n$ & $0.740^{\mathrm{a}} \pm 0.03$ & $0.856^{b} \pm 0.06$ & $0.83^{\mathrm{ab}} \pm 0.02$ & $0.783^{a b} \pm 0.04$ & $0.784^{\mathrm{ab}} \pm 0.02$ & $0.783^{\mathrm{ab}} \pm 0.03$ \\
\hline
\end{tabular}

concentration while no significant increase was observed afterward. The lowest consistency index (K) was found in emulsions stabilized with $6.0 \%$ of MS while an increase was observed at all the remaining concentrations, even though with no significant differences among them $(\mathrm{P}<$ 0.05). From these data, it could be concluded that consistency index largely remained unaffected by increasing starch concentration while the flow behavior was only significantly affected up to a certain level (6-8\% of MS) and afterward it also remained unaffected by increasing starch concentrations.

\section{Creaming stability of o/w Pickering emulsions}

Stability of the Pickering emulsions was investigated by the evaluation of the creaming index $(\mathrm{CI})$ as a parameter that could indicate the extent of droplet aggregation in an emulsion, which in turn affects its physical stability. The higher the creaming index, the more the droplets clump together (Sun-Waterhouse et al., 2013). Figure 7 shows the CI of o/w Pickering emulsions over a storage period of 1 month at room temperature. It is possible to note that the higher the starch concentration, the lower 


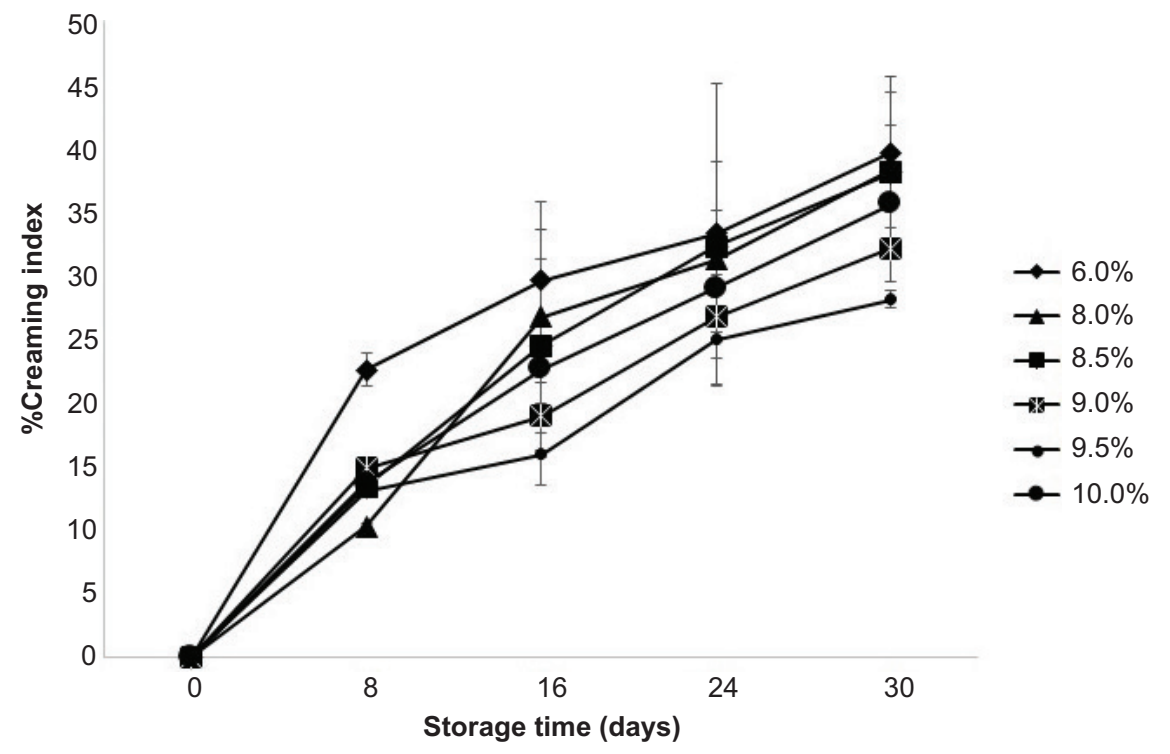

Figure 7. Effect of storage time on creaming index stability of o/w Pickering emulsions prepared with high dynamic pressure and modified corn starch at different concentrations $(6.0-10.0 \%)$.

the CI observed. On the 30th day of storage, the $6.0 \%$ MS emulsion showed the highest CI of $40 \% \pm 1$ while the 9.5\% MS systems showed the lowest CI $(28 \% \pm 1)$ and such differences were statistically significant compared to the other MS concentrations $(\mathrm{P}<0.05)$. These results are in agreement with the findings of other authors who evaluated the stability of Pickering emulsions stabilized with native and modified lauroylated starch and concluded that increasing the modified starch concentration increases the stability of the Pickering emulsions (LealCastañeda et al., 2018).

The enhanced creaming stability as a consequence of increased starch concentration may be related to a higher emulsion viscosity and to the formation of a starch particles network in which oil droplets are embedded and immobilized, as previously observed in Figure 5 and also demonstrated by other authors (Villamonte et al., 2016). A further mechanism of stabilization may be ascribed to the occurrence of starch-fatty acid complexes promoted by the homogenization process, which provided effective stabilization against coalescence and enhanced the Pickering emulsion stability (Meng et al., 2014).

\section{Conclusions}

In this preliminary study, the emulsification properties of corn starch particles modified by esterification with citric acid toward olive oil in model systems prepared by using $\mathrm{HPH}$ were studied for the first time. The emulsification of olive oil by using starch particles was successfully performed. The esterification of corn starch increased the emulsification properties toward olive oil and finely dispersed systems were obtained. The microscopic images demonstrated the emulsions' stabilization by the occurrence of a mixed mechanism based on Pickering phenomena by solid starch particles absorbed on the $\mathrm{o} / \mathrm{w}$ interface and the formation of a starch network able to entrap oil particles. The flow properties of the Pickering emulsions showed a shear-thinning non-Newtonian behavior; increasing the starch concentration enhanced the emulsion physical stability as evaluated by the creaming index by improving the oil particles entrapment within the starch network. Further work is needed to explore the emulsifying properties and exploitability of starch particles in more complex food systems formulated with olive oil as the lipid phase.

\section{References}

Abend, S., Bonnke, N., Gutschner, U. and Lagaly, G., 1998. Stabilization of emulsions by heterocoagulation of clay minerals and layered double hydroxides. Colloid and Polymer Science 276(8): 730-737. https://doi.org/10.1007/s003960050303

Alimi, B.A. and Workneh, T.S., 2018. Structural and physicochemical properties of heat moisture treated and citric acid modified acha and iburu starches. Food Hydrocolloids 81: 449-455. https://doi.org/10.1016/j.foodhyd.2018.03.027

Aveyard, R., Binks, B.P. and Clint, J.H., 2003. Emulsions stabilised solely by colloidal particles. Advances in Colloid and Interface Science 100: 503-546. https://doi.org/10.1016/ S0001-8686(02)00069-6

Berton-Carabin, C.C. and Schroën, K., 2015. Pickering emulsions for food applications: background, trends, and challenges. Annual Review of Food Science and Technology 6: 263-297. https://doi.org/10.1146/annurev-food-081114-110822 
Binks, B. and Lumsdon, S., 2000. Effects of oil type and aqueous phase composition on oil-water mixtures containing particles of intermediate hydrophobicity. Physical Chemistry Chemical Physics 2(13): 2959-2967. https://doi.org/10.1039/b002582h

Błaszczak, W., Valverde, S. and Fornal, J., 2005. Effect of high pressure on the structure of potato starch. Carbohydrate Polymers 59(3): 377-383. https://doi.org/10.1016/j.carbpol.2004.10.008

Dickinson, E., 2012. Use of nanoparticles and microparticles in the formation and stabilization of food emulsions. Trends in Food Science \& Technology 24(1): 4-12. https://doi.org/10.1016/j. tifs.2011.09.006

Dickinson, E., 2020. Advances in food emulsions and foams: reflections on research in the neo-Pickering era. Current Opinion in Food Science 33: 52-60. https://doi.org/10.1016/j. cofs.2019.12.009

Fang, J., Fowler, P., Tomkinson, J. and Hill, C., 2002. The preparation and characterisation of a series of chemically modified potato starches. Carbohydrate Polymers 47(3): 245-252. https://doi. org/10.1016/S0144-8617(01)00187-4.

Farajpour, R., Djomeh, Z.E., Moeini, S., Tavakolipour, H. and Safayan, S., 2020. Structural and physico-mechanical properties of potato starch-olive oil edible films reinforced with zein nanoparticles. International Journal of Biological Macromolecules 149: 941-950. https://doi.org/10.1016/j.ijbiomac.2020.01.175

Friberg, S., Larsson, K. and Sjoblom, J., 2003. Food emulsions. 4th ed. CRC Press, NewYork, NY.

Ge, S., Xiong, L., Li, M., Liu, J., Yang, J., Chang, R., Liang, C. and Sun, Q., 2017. Characterizations of Pickering emulsions stabilized by starch nanoparticles: influence of starch variety and particle size. Food Chemistry 234: 339-347. https://doi.org/doi. org/10.1016/j.foodchem.2017.04.150

Ghanbarzadeh, B., Almasi, H. and Entezami, A.A., 2011. Improving the barrier and mechanical properties of corn starch-based edible films: effect of citric acid and carboxymethyl cellulose. Industrial Crops and products 33(1): 229-235. https://doi. org/10.1016/j.indcrop.2010.10.016

Jeon, Y.S., Lowell, A.V. and Gross, R.A., 1999. Studies of starch esterification: reactions with alkenylsuccinates in aqueous slurry systems. Starch-Stärke 51(2-3): 90-93. https://doi. org/10.1002/(SICI)1521-379X(199903)51:2\%3C90::AIDSTAR90\%3E3.0.CO;2-M

Jiangping, Y., Luo, S., Huang, A., Chen, J., Liu, C. and McClements, D.J., 2019. Synthesis and characterization of citric acid esterified rice starch by reactive extrusion: a new method of producing resistant starch. Food Hydrocolloids 92: 135-142. https://doi.org/10.1016/j.foodhyd.2019.01.064

Khan, F. and Ahmad, S.R., 2013. Polysaccharides and their derivatives for versatile tissue engineering application. Macromolecular Bioscience 13(4): 395-421. https://doi. org/10.1002/mabi.201200409

Kim, J.Y., Lee, Y.K. and Chang, Y.H., 2017. Structure and digestibility properties of resistant rice starch cross-linked with citric acid. International Journal of Food Properties 20: 2166-2177. https:// doi.org/10.1080/10942912.2017.1368551

Królikowska, K., Fortuna, T., Pietrzyk, S. and Gryszkin, A., 2017. Effect of modification of octenyl succinate starch with mineral elements on the stability and rheological properties of oil-inwater emulsions. Food Hydrocolloids 66: 118-127. https://doi. org/10.1016/j.foodhyd.2016.12.012

Leal-Castañeda, E.J., García-Tejeda, Y., Hernández-Sánchez, H., Alamilla-Beltrán, L., Téllez-Medina, D.I., CalderónDomínguez, G., Garcia, H.S. and Gutiérrez-López, G.F., 2018. Pickering emulsions stabilized with native and lauroylated amaranth starch. Food Hydrocolloids 80: 177-185. https://doi. org/10.1016/j.foodhyd.2018.01.043

Lee, Y.-K. and Chang, Y.H., 2019. Structural and in vitro digestibility properties of esterified maca starch with citric acid and its application as an oil-in-water $(\mathrm{O} / \mathrm{W})$ Pickering emulsion stabilizer. International Journal of Biological Macromolecules 134: 798-806. https://doi.org/10.1016/j.ijbiomac.2019.05.081

Li, C., Li, Y., Sun, P. and Yang, C., 2013. Pickering emulsions stabilized by native starch granules. Colloids and Surfaces A: Physicochemical and Engineering Aspects 431: 142-149. https://doi.org/10.1016/j.colsurfa.2013.04.025

Loisel, C., Cantoni, P. and Doublier, J., 1998. Structure des empois d'amidon en relation avec leur comportement rhéologique. Paper presented at the 10 Rencontres Agoral, Massy, France, April 22-25.

Marefati, A., Wiege, B., Haase, N., Matos, M. and Rayner, M., 2017. Pickering emulsifiers based on hydrophobically modified small granular starches-part I: manufacturing and physico-chemical characterization. Carbohydrate Polymers 175: 473-483. https:// doi.org/10.1016/j.carbpol.2017.07.044

Mbougueng, P., Tenin, D., Scher, J. and Tchiégang, C., 2012. Influence of acetylation on physicochemical, functional and thermal properties of potato and cassava starches. Journal of Food Engineering 108(2): 320-326. https://doi.org/10.1016/j. jfoodeng.2011.08.006

McClements, D.J. and Gumus, C.E., 2016. Natural emulsifiers-biosurfactants, phospholipids, biopolymers, and colloidal particles: molecular and physicochemical basis of functional performance. Advances in Colloid and Interface Science 234: 3-26. https:// doi.org/10.1016/j.cis.2016.03.002

Meng, S., Ma, Y., Sun, D.-W., Wang, L. and Liu, T., 2014. Properties of starch-palmitic acid complexes prepared by high pressure homogenization. Journal of Cereal Science 59(1): 25-32. https:// doi.org/10.1016/j.jcs.2013.10.012

Qian, X., Lu, Y., Xie, W. and Wu, D., 2020. Viscoelasticity of olive oil/ water Pickering emulsions stabilized with starch nanocrystals. Carbohydrate Polymers 230: 115575. https://doi.org/10.1016/j. carbpol.2019.115575

Ravera, F., Dziza, K., Santini, E., Cristofolini, L. and Liggieri, L., 2020. Emulsification and emulsion stability: the role of the interfacial properties. Advances in Colloid and Interface Science 288: 102344. https://doi.org/10.1016/j.cis.2020.102344

Rezaei, R., Khomeiri, M., Kashaninejad, M., Aalami, M. and MazaheriTehrani, M., 2017. Steady and dynamic rheological behaviour of frozen soy yogurt mix affected by resistant starch and $\beta$-glucan. International Journal of Food Properties 20(Suppl. 3): S2688S2695. https://doi.org/10.1080/10942912.2017.1397692

Rubens, P. and Heremans, K., 2000. Pressure-temperature gelatinization phase diagram of starch: an in situ Fourier 
transform infrared study. Biopolymers: Original Research on Biomolecules 54(7): 524-530. https://doi.org/10.1002/10970282(200012)54:7\%3C524::AID-BIP50\%3E3.0.CO;2-Y

Saari, H., Heravifar, K., Rayner, M., Wahlgren, M. and Sjöö, M., 2016. Preparation and characterization of starch particles for use in Pickering emulsions. Cereal Chemistry 93(2): 116-124. https://doi.org/10.1094/CCHEM-05-15-0107-R

Stute, R., Klingler, R., Boguslawski, S., Eshtiaghi, M. and Knorr, D., 1996. Effects of high pressures treatment on starches. Starch-Stärke 48(11-12): 399-408. https://doi.org/10.1002/ star.19960481104

Sun-Waterhouse, D., Edmonds, L., Wadhwa, S. and Wibisono, R., 2013. Producing ice cream using a substantial amount of juice from kiwifruit with green, gold or red flesh. Food Research International 50(2): 647-656. https://doi.org/10.1016/j. foodres.2011.05.030

Tavernier, I., Wijaya, W., Van der Meeren, P., Dewettinck, K. and Patel, A.R., 2016. Food-grade particles for emulsion stabilization. Trends in Food Science \& Technology 50: 159-174. https:// doi.org/10.1016/j.tifs.2016.01.023

Timgren, A., Rayner, M., Dejmek, P., Marku, D. and Sjöö, M., 2013. Emulsion stabilizing capacity of intact starch granules modified by heat treatment or octenyl succinic anhydride. Food Science \& Nutrition 1(2): 157-171. https://doi.org/10.1002/fsn3.17

Villamonte, G., Jury, V. and de Lamballerie, M., 2016. Stabilizing emulsions using high-pressure-treated corn starch. Food Hydrocolloids 52: 581-589. https://doi.org/10.1016/j. foodhyd.2015.07.031

Wang, B., Li, D., Wang, L.-j., Chiu, Y. L., Chen, X. D. and Mao, Z.-h., 2008. Effect of high-pressure homogenization on the structure and thermal properties of maize starch. Journal of Food Engineering 87(3): 436-444.
Wu, J. and Ma, G.H., 2016. Recent studies of Pickering emulsions: particles make the difference. Small 12(34): 4633-4648. https:// doi.org/10.1002/smll.201600877

Xiao, J., Li, Y. and Huang, Q., 2016. Recent advances on food-grade particles stabilized Pickering emulsions: fabrication, characterization and research trends. Trends in Food Science \& Technology 55: 48-60. https://doi.org/10.1016/j.tifs.2016.05.010

Xie, X. and Liu, Q., 2004. Development and physicochemical characterization of new resistant citrate starch from different corn starches. Starch-Stärke 56(8): 364-370. https://doi.org/10.1002/ star.200300261

Yang, Y., Fang, Z., Chen, X., Zhang, W., Xie, Y., Chen, Y., \& Yuan, W., 2017. An Overview of Pickering emulsions: solid-particle materials, classification, morphology, and applications. Frontiers in Pharmacology 8(287). https://doi.org/10.3389/fphar.2017.00287

Ye, F., Miao, M., Jiang, B., Campanella, O.H., Jin, Z. and Zhang, T., 2017. Elucidation of stabilizing oil-in-water Pickering emulsion with different modified maize starch-based nanoparticles. Food Chemistry 229: 152-158. https://doi.org/doi.org/10.1016/j. foodchem.2017.02.062

Zhang, B., Mei, J.-Q., Chen, B. and Chen, H.-Q., 2017. Digestibility, physicochemical and structural properties of octenyl succinic anhydride-modified cassava starches with different degree of substitution. Food Chemistry 229: 136-141. https://doi. org/10.1016/j.foodchem.2017.02.061

Zhou, J., Tong, J., Su, X. and Ren, L., 2016. Hydrophobic starch nanocrystals preparations through crosslinking modification using citric acid. International Journal of Biological Macromolecules 91: 1186-1193. https://doi.org/10.1016/j.ijbiomac.2016.06.082 